\title{
Pathogenesis of oral squamous cell carcinoma- An update
}

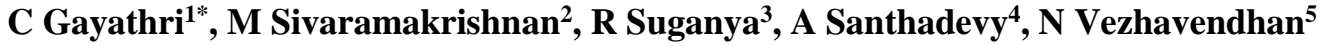 \\ ${ }^{1}$ Post Graduate, ${ }^{2,3}$ Reader, ${ }^{4}$ Professor and Head, ${ }^{5}$ Professor, Dept. of Oral \& Maxillofacial Pathology \& Oral Microbiology, \\ Indira Gandhi Institute of Dental Sciences, Sri Balaji Vidyapeeth (Deemed to be university), Puducherry, India
}

\section{*Corresponding Author: C Gayathri}

Email: gayathri02.bds@gmail.com

\begin{abstract}
Oral cancer is the sixth most common malignancy in the world. Oral cancer is of major concern in Southeast Asia primarily because of the deleterious habits such as smoking, betel nut chewing and alcohol consumption. Despite recent advances in cancer diagnoses and therapies, the survival rate of oral cancer patients has remained at a dismal 50\% in the last few decades. This paper is an overview of the various etiological agents and risk factors implicated in the development of oral cancer.
\end{abstract}

Keywords: Tobacco, Alcohol, Squamous cell carcinoma, Risk factors.

\section{Introduction}

Oral squamous cell carcinoma in India ranks first among male and third among female. ${ }^{1}$ Oral carcinoma is a multistep process develops by genetic alterations, genetic predisposition, environmental influences such as tobacco, alcohol, chronic inflammation, viral infections, Diet and nutrition, Fungal infections, Dental factors, Trauma, Age, Immune suppression. ${ }^{2}$ Certain etiological factors such as tobacco and alcohol consumption is well established, however 15 to $20 \%$ oral cancer develops in patients without this habits. ${ }^{3}$

This paper is an overview of etiological factors and molecular changes in development of oral squamous cell carcinoma.

\section{Etiological Factors}

\section{Tobacco}

The carcinogen in tobacco causes DNA adducts. This DNA adducts found to play main role in chemical carcinogenesis. If this DNA adducts are repaired by DNA repair pathways, they revert back to normal state. An important thing to be noted is metabolic activation varies between individuals such as genetic polymorphism in carcinogen. Metabolism of gene is an important determinant of DNA adducts levels, also it helps in identification of smokers with increased risk for cancers. More than $90 \%$ of oral squamous cell carcinoma has been reported because of tobacco habits. ${ }^{4}$

The flow chart depicts the role of tobacco and its carcinogens in development of oral squamous cell carcinoma. $^{5}$

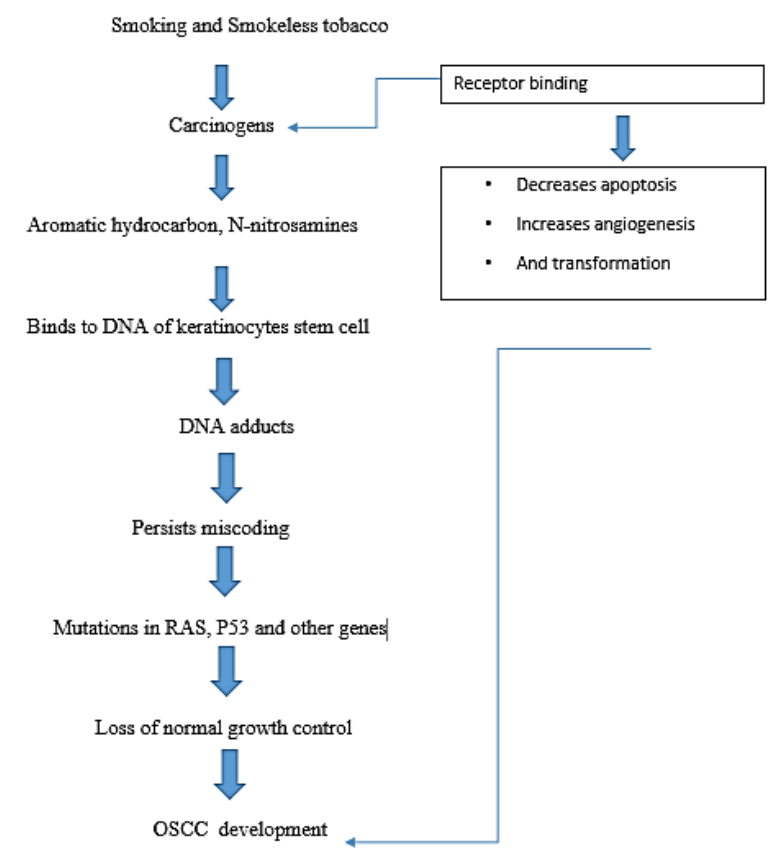

\section{Alcohol}

The carcinogens that are present in the alcohol has been implicated in development of oral cancer. Consumption of alcohol and tobacco found to act synergistically and pave way in development of oral cancer. In few studies alcohol itself is found to be an independent risk factor in development of oral epithelial dysplasia and oral cancer. ${ }^{6}$ Alcohol leads to increase permeability of oral mucosa, causing alteration in morphology, characterized by epithelial atrophy, leading to easier penetration of carcinogen in the oral mucosa. ${ }^{5}$ 
Alcohol

$\Downarrow$

Carcinogens- Acetaldehyde, N-nitroso compounds, Mycotoxin Urethan, Inorganic arsenic and others

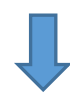

Interferes with DNA synthesis and repair, Induces sister chromatid exchanges and specific gene mutation, Inhibits enzyme 6-methylguani transferase.

\section{Viruses}

Viruses have found to play role in development of oral squamous cell carcinoma. Viral genes are proto oncogenes they become oncogene once they get inserted in to hosts DNA leading to malignant transformation. Viral infections are of latent or chronic nature are mainly responsible for inducing malignant transformation by disrupting host cell cycle, which in turn affects cell growth and proliferation. The viruses that are implicated in oral cancer development are human herpes virus Epstein- Barr virus (EBV), Human papillomavirus (HPV) and Herpes simplex virus.

However the role of Epstein Barr virus and Herpes simplex virus is still unclear. ${ }^{5}$

\section{Human Papilloma Virus}

Human papilloma viruses are the most common virus that play role in development of oral squamous cell carcinoma. HPV type 16 and 18 are found to be the major cause in development of OSCC. ${ }^{7}$

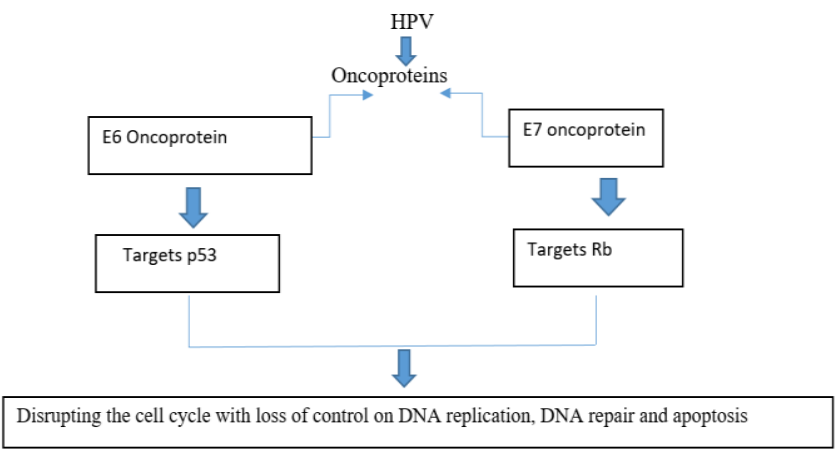

\section{Other Risk Factors}

In population based studies to determine role of genetic or familial disposition to oral cancer are found to be associated with coexisting with risk factors like smoking and alcohol. ${ }^{8}$

Low intake of fruits and vegetables predisposes to increased risk of cancer. Individuals consuming alcohol found to less amount of fruits and vegetables which further increases the rate of development of OSCC. ${ }^{5}$

Dental factors like poor oral hygiene, sharp or fractures cusp, ill -fitting denture are found to pave way in development of OSCC with presence of other risk factors. ${ }^{5}$

Occupational risks like individuals those who are exposed to sunlight, ultraviolet rays are prone for cancer development in lips. ${ }^{5}$

\section{Conclusion}

Even though several risk factors play role in development of oral cancer, the most common and established factor is tobacco. Nevertheless, many patients are diagnosed with oral cancer despite abstaining from known lifestyle or environmental risk factors like genetic susceptibility are believed to play the causative role. Therefore it is important for the clinicians to be aware of the risk factors that are implicated in development of oral cancer. Also in patients with history of known risk factors, dentists must look carefully for early signs of oral cancer during routine examination.

\section{Source of funding}

None.

\section{Conflict of interest}

None.

\section{References}

1. Salian V, Dinakar C, Shetty P, Ajila V. Etiological trends in oral squamous cell carcinoma: A retrospective institutional study. Cancer Transl Med 2016;2(2):33.

2. Choi S, Myers JN. Molecular pathogenesis of oral squamous cell carcinoma: implicationsfor therapy. J Dent Res 2008;87(1):14-32.

3. Williams HK. Molecular pathogenesis of oral squamous carcinoma. Mol Pathol 2000;53(4):165.

4. Jiang X, Wu J, Wang J, Huang R. Tobacco and oral squamous cell carcinoma: A review of carcinogenic pathways. Tobacco Induced Diseases. 2019;17.

5. Kumar M, Nanavati R, Modi TG, Dobariya C. Oral cancer: Etiology and risk factors: A review. J Cancer Res Ther 2016;12(2):458. 
6. Evstifeeva TV, Zaridze DG. Nass use, cigarette smoking, alcohol consumption and risk of oral and oesophageal precancer. Eur J Cancer B Oral Oncol 1992;28B:29-35.

7. Karja I, Syrjanen S, Usenious T, Vornanen M, Collan Y. Oral cancer in children under 15 years of age: A Clinicopathologic and Virological study. Acta Otolaryngol Suppl 2008;449:145-9.

8. Hernandez G, Arriba L, Jimenez C, Bagan JV, Rivera B, Lucas M, et al. Rapid progression from oral leukoplakia to carcinoma in an immunosuppressed liver transplant recipient. Oral Oncol 2003;39:87-90.

How to cite this article: Gayathri $\mathrm{C}$, Sivaramakrishnan M, Suganya R, Santhadevy A, Vezhavendhan N. Pathogenesis of oral squamous cell carcinoma- An update. Int Dent $J$ Student Res 2019;7(4):84-6. 